\section{Anthropology and race}

SIR - While the race issues you raise are indeed serious, they miss the nub of the problem. And that problem, I believe, is exacerbated rather than solved in your leading article ${ }^{1}$. The problem is the deprofessionalization of physical anthropology as a scientific discipline, and the substitution of folk wisdom for informed contemporary professional judgements. This is precisely what Dr Roger Bannister, the focus of your leading article, has done. And yet you did not cite a modern work in the field of physical anthropology in response. In fact the field is considerably different from your representation of it. The idea that the human species is naturally partitioned into a few large groups is antiquated by several decades, having been replaced by the recognition that (1) human biological variation is simply geographically patterned (people are similar to those nearby and different from those far away); and (2) large-scale racial clusters are cultural constructs, arbitrarily ignoring considerable diversity in order to contrast extremes ${ }^{2}$.

Diverse human groups do of course sometimes consistently perform differently in certain arenas. The folk interpretation of this is that it reflects constitutional differences among them. On the other hand, anthropologists in this century have demonstrated that the human mind and the human form are possessed of considerable developmental malleability, through studies of similar peoples in different circumstances and different peoples in similar circumstances ${ }^{3}$. Although there is no way at present to study the genetics of ability or potential, what we do know of modern physical anthropology strongly undermines the assumption that consistent differences in observed performance are invariably or even primarily caused by hereditary or constitutional differences. Some may be, but a demonstration in any particular case demands considerably greater standards of validation than simply the observation of a consistent difference in performance. Certainly social history - the varied successes of different minorities at different times in different endeavours - suggests that there are no great differences in human potential at the level of populations. The "cognitive elite" described in The Bell Curve - Ashkenazi Jewry - was actually considered to have such corrupt "germ plasm" in the 1920 s that legislation was deemed necessary to restrict their further immigration into the United States. Apparently they've improved since then. To the extent that individual differences may exist, we lack a social mechanism for evaluating and cultivating everyone's diverse potentials. What we do know is that it simply is neither scientifically valid

\section{Jonathan Marks}

nor admirably humanitarian to evaluate them by recourse to folk prejudices about the potentials of their groups.

The tragedy of the Human Genome Diversity Project (HGDP) is that it shows a different face of the same general problem. Anthropologists have been studying genetics of non-Western people for decades, but never with such great fanfare. Unfortunately, they were not among the project's original designers; the HGDP was formulated initially by well-intentioned molecular population geneticists, with largely a folk knowledge of anthropology ${ }^{4-6}$. Like Bannister, they tacitly assumed that the relevant anthropological issues were largely intuitive, and that modern anthropology itself could be largely ignored. They are now having to cope with the consequences of that assumption.

Department of Anthropology,

Yale University,

New Haven, Connecticut 06511, USA

1. Nature 377, 183 (1995).

2. Montagu, A. (ed.) The Concept of Race (Macmillan, New York, 1964).

3. Bogin, B. Patterns of Human Growth (Cambridge University Press, New York, 1988)

Jackson, F. L. C. Anthrop. Newsl. 35, 19 (1994).

5. Lasker, G. Anthrop. Newsl. 35, 19 (1994).

6. Marks, J. Anthrop. Newsl. 36, 72 (1995.

see also Book Review on p. 589.

\section{Climate change}

SIR - In his article "Climate change: a successful prediction?", Tom M. L. Wigley (Nature 376, 463-464; 1995) comments on the study of Mitchell et al. (Nature 376, 501-504; 1995) and undertakes a balanced review of recent findings emerging from climate modelling efforts.

While there is considerable work done on global-scale assessments of the phenomenon of climate change and its impact, confidence in regional-scale assessments based on global climate models is still low. Mitchell makes the point that "the improvement in simulation of specific regions is equivocal". In fact, much of the pioneering work being carried out at centres of excellence such as the Hadley Centre in the United Kingdom, the Max Planck Institute in Germany and the Oak Ridge National Laboratories in the United States appears to lose sight of the need to refocus climate studies by making a transition from global generalities to regional/country specifics.

Leading atmospheric scientists in India are of the opinion that very few of the nuances associated with monsoons have been recognized or incorporated in models. And, unfortunately, despite the century-old tradition of meteorological forecasting, climate modelling in India is still at an early stage and lacks the financial and computational resources to fill this crucial gap in international research.

South Asia, with its region-specific, agro-climatic zones, food security problems, rising population and economic growth it must be squarely recognized - presents an immense challenge and opportunity to further and promote international scientific cooperation in this frontier field. This alone will help in assessing regional and subregional effects and provide an appropriate input to policy-making. The grim alternative is to negotiate climate change against the backdrop of an asymmetry of scientific information and political influence.

\section{K. Vinayak Rao}

Centre for Science and Environment,

41 Tughlakabad Institutional

Area (Near Batra Hospital),

New Delhi - 110 062, India

\section{Exploited authors}

SIR - I share Keith Frayn's view (Nature 375, 100; 1995) of the attitude of publishers towards authors. About a year ago, I was invited to contribute a chapter for a new volume of the Encyclopedia of Fluid Mechanics, to be published by Gulf Publishing Company in the United States. I was given a submission date of 15 February 1995 and the editor sent me all the relevant documents.

In order to meet the deadline and to keep up with my own work, I paid a typist and a draughtsman from my own pocket. I also spent a lot of time seeking permission to reproduce material from other publications. No fee was offered but I was told I would receive a complimentary copy of the volume concerned. As I had been asked to write the chapter, I assumed that my expenses would be reimbursed.

The editor stopped communicating with me when the chapter was almost ready. In spite of my letters and fax messages (which are quite expensive in India), I have heard nothing more since then from either the editor or the publisher.

Imagine my surprise, therefore, when, in June 1995, the same editor asked me to contribute a chapter on a different subject to an Encyclopedia of Polymer Processing Technology, to be published this time by Marcel Dekker. What should I say to the editor? If I agree, will I hear from him again this time? Where do I stand with regard to the earlier contract?

I spent a great deal of time and some money preparing the earlier chapter. I can earn more money, but I cannot replace the lost time. Editors and publishers like those I have mentioned are simply exploiting willing authors.

\section{Anil Kumar}

Physical Chemistry Division,

National Chemical Laboratory,

Pune, 411008 India 